\title{
González Apodaca, Erica (2016). Apropiaciones escolares en contextos etnopolíticos. Experiencias de egresados de la educación intercultural comunitaria ayuujk. México: Centro de Investigación y Estudios Superiores en Antropología Social
}

\author{
Gabriela Czarny*
}

E llibro Apropiacionesescolaresencontextosetnopolíticos. Experiencias de egresados de la educación intercultural comunitaria ayuujk, de Erica González Apodaca, editado por CIESAS en 2016, resulta una pieza clave en el estudio de los procesos de apropiación escolar y de profesionalización indígena en México. La investigación de González tiene como referente la conformación y la experiencia del proyecto educativo conocido como Bachillerato Integral Comunitario Ayuujk Polivalente (BICAP), que inició a nivel de la enseñanza media superior a mediados de los años noventa en la comunidad de Santa María Tlahuitoltepec, Oaxaca, y que representó una de las primeras propuestas de este nivel educativo orientada a la actualización de la identidad ayuujk (mixe) de los jóvenes estudiantes mediante sus competencias escolar-profesionales y su arraigo comunitario. A través del BICAP se promovió un proyecto que claramente surgió desde la comunidad y que disputa el espacio de lo escolar, con una estrategia que busca la recuperación de bases etnopolíticas y comunitarias sin desarticularse completamente de las políticas educativas impulsadas por el Estado.

Este trabajo de corte histórico y etnográfico se teje sobre dos ejes centrales relacionados: la profesionalización indígena como proyecto etnopolítico y los procesos de subjetividad de los jóvenes indígenas. Almismo tiempo, el ejercicio de historizar esos procesos bajo el lente de las luchas de los pueblos originarios de Oaxaca por el reconocimiento es en sí un aporte sustancial.

El campo de estudio sobre la profesionalización indígena -enunciado en las últimas décadas en perspectivas comunitarias, interculturales o indígenastiene en México sus primeros antecedentes en la historia de lo que conocemos como educación escolar indígena vinculada al Estado y a las políticas indigenistas. En diversos trabajos se han analizado las instancias y programas que desde la década de los treinta del siglo XX han marcado la educación escolar indígena, así como el papel de los antropólogos y lingüistas en esos procesos. Puede reconocerse que hasta antes de los años sesenta esas acciones de escolarización y profesionalización tuvieron un enfoque según el cual los pueblos eran tratados en el discurso académico y político como sectores campesinos, caracterizados por su analfabetismo, y debido a ello por su condición de pobreza cultural, necesitados de incorporase a la moderna nación para su desarrollo. A partir de los años setenta, y con el impulso de los movimientos etnopolíticos, las demandas por escolarización y

* Gabriela Czarny. Universidad Pedagógica Nacional, Ajusco, Ciudad de México. Correo electrónico: gacza_2006@yahoo.com.mx.

Recibida: 12 de abril de 2018 
profesionalización adquirieron otras posiciones marcadas por el discurso de la descolonización y el reconocimiento de los pueblos como sujetos de derechos e interlocutores para la definición e implementación de políticas públicas en las que quepamos todos.

Esta investigación, por su carácter longitudinal, retomando material de campo de varias generaciones de estudiantes, ubica a su autora realizando una intervención metodológica que le permite un análisis a profundidad. Indudablemente, ello también remite a los andamiajes teóricos y conceptuales que teje para abordar procesos complejos de escolarización y profesionalización, en este caso de jóvenes indígenas hombres y mujeres en su mayoría mixes - , atravesados por relaciones marcadas por las desigualdades sociales y de género, recuperando relatos biográficos que abren un escenario de realidades multifacéticas.

Entre las preguntas detonadoras de su trabajo, producto también de una inmersión entre los ayuujk en Tlahuitoltepec, destaca la siguiente: icómo (algunos de) los egresados y egresadas del BICAP se apropiaron transformativamente de la propuesta formativa etnopolítica y qué significado le atribuyeron a sus experiencias escolares, principalmente en relación con la profesionalización y la etnización, entendida como formación reivindicativa de la identidad cultural ayuujk y la cultura comunitaria?

Esta etnografía contempla varias estrategias vinculadas a tiempos y espacios diversos. El grupo de referencia analítica y dialogal estaba integrado por una cohorte de estudiantes egresados del BICAP entre los años 1996 y 2003, todos de Tlahuitoltepec, con perfiles y trayectorias diferentes. En su mayoría residían, al momento de la investigación, en la comunidad, y realizaban movimientos migratorios a las ciudades; algunos de ellos continuaron estudios a nivel superior y otros no. Si bien la organización argumental del texto tiene su centro en discursos y relatos de jóvenes egresados del BICAP, se fortalece el análisis al recuperar testimonios de otros actores como directivos y maestros de esa institución, así como de padres de familia, autoridades de la comunidad y autoridades educativas de la entidad y la federación.
Las trayectorias y las experiencias personales de estos egresado orientaron la interpretación que hace la autora sobre los sentidos escolares y étnicos socialmente apropiados por éstos, identificando las interconexiones que dibujan la complejidad de escenarios en los que el género, la clase social y la condición migratoria marcan procesos de desigualdad en las historias personales y profesionales.

Profundiza en la génesis de lo que fue la configuración y constitución del BICAP como proyecto educativo comunitario - lo que incluye fuerzas políticas del contexto regional y nacional y tensiones por el modelo escolar-, al mismo tiempo que visibiliza lo que en Tlahuitoltepec representan las relaciones de parentesco y la vitalidad étnica de la comunidad. Esas relaciones, en la perspectiva de la autora, tienen un fuerte sentido subjetivante e implican una lealtad primordial para los jóvenes egresados, situaciones que llega a confrontar con la búsqueda de proyectos de vida personales y los deseos de autonomía y movilidad. Sin embargo, lejos de anteponer el lente de la comunidad como unidad compacta, muestra la heterogeneidad de condiciones familiares de los interlocutores involucrados en este estudio y de acceso diferencial de éstos al capital cultural y escolar que los define, en una comunidad que se rige y organiza por el sistema de usos y costumbres en el que los jóvenes asumen lugares y compromisos específicos.

En los últimos veinte años la ubicación de lo juvenil indígena como categoría abrió caminos para analizar, entre otros aspectos, los procesos de subjetividad de este sector. En tal sentido, al igual que en otras investigaciones en Latinoamérica, el texto muestra lo diverso de lo juvenil indígena, así como las distintas formas de posicionarse como una o un joven en la comunidad de Tlahuitoltepec. En esta veta señala que la escolarización y la profesionalización de hombres y mujeres mixes traen consigo reconfiguraciones de las identidades étnicas y de género que transforman las representaciones subjetivas y las prácticas objetivas de ser mujer y ser varón en la comunidad, y que modifican concepciones sobre la familia, el matrimonio y los roles de género. 
Otro de los aspectos que es de resaltar en este libro es la documentación de las estructuraciones y sentidos pedagógicos que configuraron el proyecto BICAP, que como tal dejó de funcionar hacia el año 2004. En esa descripción de la propuesta pedagógica se analizan: 1) la estrategia pedagógica del "trabajo por proyectos" estudiantiles - prevista por el modelo heredado del Centro de Bachillerato Tecnológico Agropecuario (CBTA) - , que se apropia y resignifica desde el sentido étnico-comunitario del proyecto;2) el BICAP como "comunidad de práctica y de aprendizaje cooperativo", experiencia escolar que contrasta con la escuela "occidental de corte tradicional" y que se vincula más con los estilos y prácticas socioculturales vigentes en la comunidad; 3) la "estrategia de evaluación" a través de las exposiciones públicas y validación social de los aprendizajes —y también del funcionamiento y la gestión académica-, así como la presencia y uso de la lengua mixe para ello, y 4) la caracterización de "los perfiles de los maestros" que se hacen cargo de impulsar, junto con la comunidad, el proyecto educativo y configuran las identidades docentes. Estas descripciones conforman un aporte para la construcción de propuestas educativas que comenzaron a plantear, desde las comunidades, modelos pedagógicos.

Indudablemente, y entre los aspectos centrales de los que da cuenta esta investigación, se encuentra la valoración sobre los efectos del paso por el BICAP para las generaciones que en él estuvieron, considerando si con ese proyecto educativo comunitario se generó un empoderamiento étnico al reforzar en positivo la diferencia cultural que históricamente ha sido señalada como estigma, desvalor y negación de sujetos y pueblos, en este caso de los ayuujk. Estas perspectivas de fortalecimiento étnico y revaloración de la cultura y las prácticas comunitarias resultan ser logros en la visión de un conjunto de egresados, es decir, el modelo pedagógico ha tenido impacto en ellos y en los compromisos que han asumido para el fortalecimiento comunitario, lo que también orientó el sentido de la profesionalización en el nivel superior de los que continuaron estudiando. Al mismo tiempo, el trabajo visibiliza otros valores de la experiencia en el BICAP referidos a los impactos que tuvo en los jóvenes mixes, tanto en los que decidieron continuar estudiando en el nivel superior, como en los que se insertaron en diferentes prácticas vinculadas a la vida comunitaria o en otros circuitos laborales en la región oaxaqueña y fuera de ella. En esta posición, se muestra que el sentido de proyecto político no parece alcanzar a todos los sujetos que pasaron por la institución. Para algunos sólo representó un espacio - aunque sí alterno al formato escolar jerárquico y autoritario hegemónico- que permitió el desarrollo de habilidades vinculadas con distintos conocimientos, así como el fortalecimiento de la seguridad personal. En estos egresados, señala Erica, la propuesta étnica del BICAP se articula débilmente al discurso reivindicativo, y más a prácticas productivas comunitarias que se actualizan para apuntalar proyectos personales dentro y fuera de la comunidad. También otros egresados dirigen críticas a este proyecto educativo como cualquier estudiante de bachillerato. En este grupo, y para los que no continuaron sus estudios en el nivel superior por múltiples razones, se advierte que resignifican sus trayectorias escolares, pero al hacerlo cuestionan la utilidad de la escuela como mecanismo de movilidad social y relativizan sus signos de "distinción”, al mismo tiempo que se posicionan como sujetos con agencia que toman decisiones vitales en sus trayectorias escolares y de vida.

Hacia el final del libro la autora problematiza la metáfora que en los campos de la profesionalización étnica y de la apropiación escolar se conoce como "los que se quedan en la comunidad" y "los que se van de la comunidad", utilizando una estrategia de "estudios en caso" de algunos de los egresados. Existe un debate en el campo antropológico y educativo que trata el tema de la migración indígena nacional y transnacional en el que se viene señalando, al igual que en el trabajo de Erica González, la importancia de las redes familiares y de paisanaje para sostener la experiencia vital fuera de la comunidad, así como los conflictivos mandatos que viven las juventudes indígenas profesionalizadas en carreras e instituciones diversas. La investigación en cuestión muestra que los profesionales indígenas 
mantienen vínculos y lealtades de distinto tipo con sus comunidades y con organizaciones étnicas, y que en diversos casos, al buscar regresar a la comunidad de origen para trabajar en ella, encuentran cuestionamientos y dificultades. Otros deciden buscar trabajo fuera de sus comunidades, sin embargo, y como se muestra, ello no representa una ruptura, sino una reformulación de las membresías e identidades étnico-comunitarias, aunque con tensiones. En este punto el análisis hace referencia a procesos de "recomunalización", como constructo que remite a un regreso material, aunque también simbólico, a la comunidad. Sin embargo, y como también se deja ver en algunos relatos, "salir de la comunidad" genera otros aprendizajes y reformula las lealtades, no por ello necesariamente de menor valor y compromiso para las luchas y la reivindicación etnopolítica.
La lectura de este libro nos lleva al replanteamiento de viejos/nuevos interrogantes como los siguientes: los sentidos de los proyectos educativos que desde el Estado se han impulsado para los pueblos indígenas aún subalternizados y racializados; el papel que juega la academia en la generación de conocimientos sobre el tema; los lugares que ocupan los profesionales y académicos indígenas en estos procesos y en la gestación de proyectos desde abajo, así como la imponente fuerza que tienen los sujetos y comunidades en acciones como las que se han articulado en torno al BICAP y a diversos proyectos en Tlahuitoltepec.

Tratar de sintetizar una obra de esta importancia en pocas páginas es una pretensión improcedente, por lo que no me queda más que invitar a su lectura y a reconocer en ella las marcas de las luchas, las voces y los aún silencios que se dejan escuchar. 